\title{
Dynamics of Mismatch Correction in the Hippocampal Ensemble Code for Space: Interaction between Path Integration and Environmental Cues
}

\author{
Katalin M. Gothard, William E. Skaggs, and Bruce L. McNaughton \\ Arizona Research Laboratories Division of Neural Systems, Memory and Aging, University of Arizona, Tucson, \\ Arizona 85724
}

\begin{abstract}
Populations of hippocampal neurons were recorded simultaneously in rats shuttling on a track between a fixed reward site at one end and a movable reward site, mounted in a sliding box, at the opposite end. While the rat ran toward the fixed site, the box was moved. The rat returned to the box in its new position. On the initial part of all journeys, cells fired at fixed distances from the origin, whereas on the final part, cells fired at fixed distances from the destination. Thus, on outward journeys from the box, with the box behind the rat, the position representation must have been updated by path integration. Farther along the journey, the place field map became aligned on the basis of external stimuli. The spatial representation was quantified in terms of population vectors. During shortened journeys, the vector shifted from an alignment with the origin to an alignment
\end{abstract}

with the destination. The dynamics depended on the degree of mismatch with respect to the full-length journey. For small mismatches, the vector moved smoothly through intervening coordinates until the mismatch was corrected. For large mismatches, it jumped abruptly to the new coordinate. Thus, when mismatches occur, path integration and external cues interact competitively to control place-cell firing.

When the same box was used in a different environment, it controlled the alignment of a different set of place cells. These data suggest that although map alignment can be controlled by landmarks, hippocampal neurons do not explicitly represent objects or events.

Key words: population vector; cell ensemble; computation; path integration; place cells; navigation
The rat hippocampus is crucial for spatial learning and navigation (O'Keefe and Nadel, 1978; Barnes, 1988; Jarrard, 1993). Although the location-specific firing of hippocampal place cells has been amply documented (O'Keefe and Dostrovsky, 1971; Olton et al., 1978; Kubie and Ranck, 1983; McNaughton et al., 1983; Muller et al., 1987; Eichenbaum et al., 1989; Wiener et al., 1989; Jung and McNaughton, 1993; Wilson and McNaughton, 1993), the factors that determine place-cell activity are not fully understood. According to the original formulation of the cognitive map hypothesis (O'Keefe and Nadel, 1978), “a place representation can be activated in either of two ways: (1) externally, by the simultaneous occurrence of two or more sensory inputs with the appropriate spatial coordinates in egocentric space; (2) internally, by an input from another place representation coupled with a signal from the motor system concerning the magnitude and orientation of a movement" (see also O'Keefe, 1976). Much subsequent work on the determinants of place fields has focused on the former of these two factors, i.e., external sensory cues; however, the observation that novel place fields can arise in darkness and persist after subsequent illumination (Quirk et al., 1990; Markus et al., 1994) indicate that location-specific firing, at least initially, can

Received May 6, 1996; revised Aug. 22, 1996; accepted Sept. 20, 1996.

This work was supported by the Office of Naval Research and NS20331 and conducted in partial fulfillment of the requirements for the degree of Doctor of Philosophy. We thank Dr. C. A. Barnes for two surgically implanted rats; Dr. D. Chialvo for useful discussions about the experiments; Drs. Carol Barnes, A. J. Fuglevand, and H. S. Kudrimoti for thoughtful comments on this manuscript; Casey Stengel for technical assistance; and Karen Weaver for help with recording.

Correspondence should be addressed to Dr. Bruce L. McNaughton, 344 Life Sciences North, University of Arizona, Tucson, AZ 85724.

Copyright (C) 1996 Society for Neuroscience $0270-6474 / 96 / 168027-14 \$ 05.00 / 0$ be independent of external input. In addition, when the task demands are changed without altering the external cues, substantial changes in place field distributions are induced (Markus et al., 1995). Furthermore, the observation that the entire place field distribution can rotate synchronously in the presence of stable visual cues (Knierim et al., 1995) suggests that place cells may be driven by self-motion signals.

Gothard et al. (1996) reported that in a landmark-based navigation task, place fields were coupled to moving objects. When rats shuttled between a variably placed box and two variably placed landmarks inside a large arena, some cells fired in stable spatial relationships to the box, whereas others fired in relation to the landmarks. These data suggested that behaviorally relevant objects establish distinct spatial reference frames in which location is encoded. Because of limited sampling in the large arena, however, object-related firing could be demonstrated only for those cells that fired in close proximity to the reference objects. Because the rats' trajectories between the box and the landmarks were highly variable, the extent to which the box or the other landmarks influenced cell activity along the journey could not be established.

The present study was designed to elucidate how the origin and destination of a journey control place fields along the route. By systematically varying the distance between the origin and the destination of a journey, the influence of these cardinal points could be measured separately.

A related objective was to establish whether cells bound to the reference frame of an object would maintain their object-related firing in a different environment. Object-related firing could, in principle, be accounted for by tuning to sensory aspects of the object (Otto and Eichenbaum, 1992; Young et al., 1994; Kor- 
A

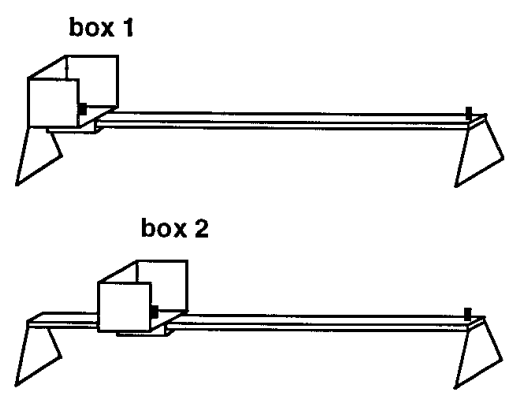

box 3

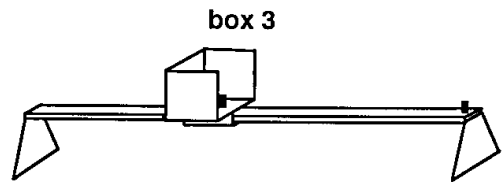

box 4
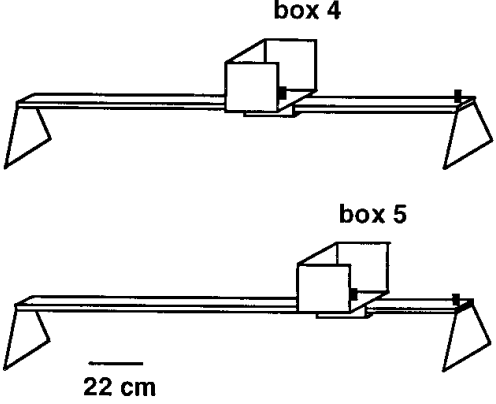

B OUTBOUND JOURNEYS

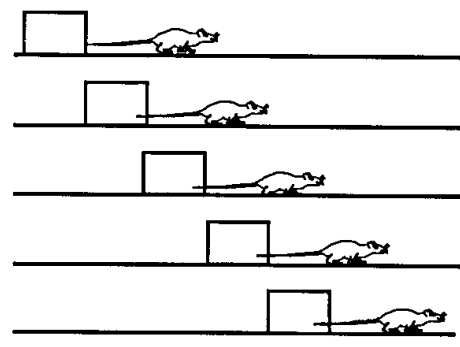

$\overline{22 \mathrm{~cm}}$

C InBOUND JOURNEYS

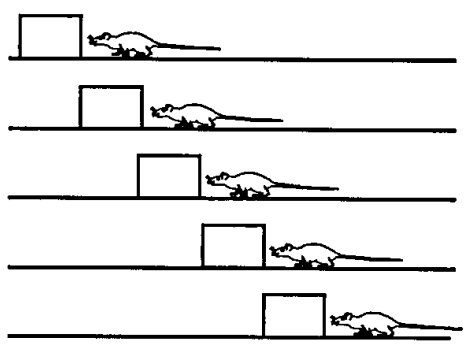

box1 out

box2 out

box3 out

box4 out

box5 out

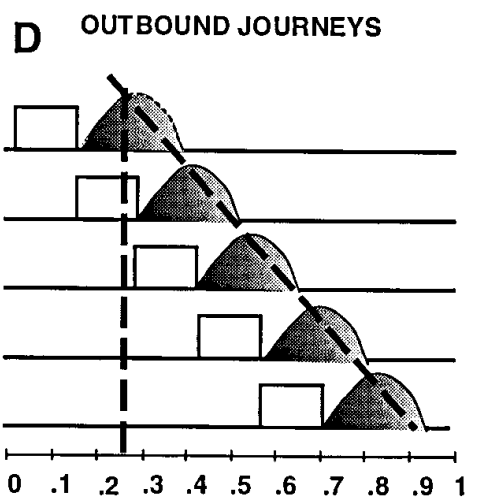

box1 in

box 2 in

box3 in

box 4 in

box 5 in

\section{E INBOUND JOURNEYS}

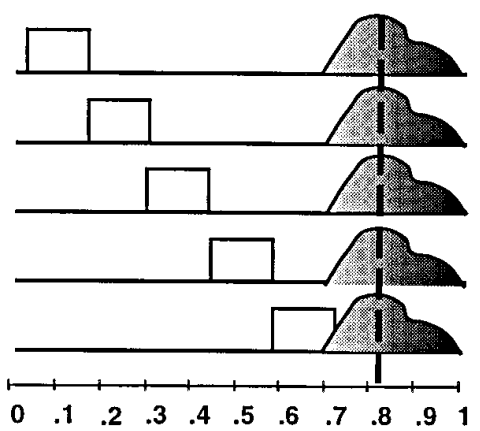

Figure 1. Behavioral apparatus and analysis methods for Experiment 1. A, Linear track (to scale) with the five box locations used as the start and end point of each journey. The $188 \times 8 \mathrm{~cm}$ track was placed across a corner of the laboratory and was surrounded by recording equipment and laboratory furniture. A $27-\mathrm{cm}$-high $\times 32$-cm-wide $\times 27$-cm-long cardboard box was mounted on the track. On each trial, the box was moved to one of five equally spaced locations. One food cup was mounted in the box and another was fixed at the opposite end of the track. During each trial, while the rat approached the fixed food cup, the box was moved to a new location to which the rat then returned. Box locations were randomly assigned, ensuring that all five locations were equally probable. $B$ shows the five types of outbound journeys, labeled box 1 out, box 2 out, etc. $C$ shows the five types of inbound journeys. $D$, The behavioral correlate of each cell was quantified by the slope of a line fitted to the firing profiles on the five different types of trials (the "displacement slope"). The figure shows firing profiles of an idealized cell with a displacement slope of 1.0 on the outbound journeys. This cell fires at the same distance from the box irrespective of the position of the box on the track. The slanted dashed line represents the regression line used to calculate the displacement slope. The vertical dashed line points to the location of the peak firing on the box1-out trials $(\sim 0.25$ for this example). E, Firing profile of an idealized cell with a displacement slope of 0.0 on the inbound journeys. The firing field of this cell remains in the same location on the track for all trial types. The vertical dashed line gives a displacement slope of 0.0 and also indicates the location of peak firing on the box 1-in trials.

shunov et al., 1996), by representation of specific behaviors or reward contingencies related to that object (Eichenbaum et al., 1987; Eichenbaum and Cohen, 1988; Breese et al., 1989; Wiener et al., 1989; Fukuda et al., 1992), or by participation in a spatial map centered on the object (Gothard et al., 1996). To distinguish among these alternatives, hippocampal cells were recorded in different environments that shared a behaviorally relevant object, a box in which each trial started and ended. If the sensory features of the box, the reward contingency, or the behavior of walking into or out of the box are responsible for box-related firing, the spatial context would make little or no difference, and the cells would maintain their box-related firing in both environments. Alternatively, if box-related cells are simply place cells, then one might expect different place field relationships in different environments (Kubie and Ranck, 1983), regardless of the presence of a common object.

Abstracts of this work have been published previously (Gothard et al., 1995; McNaughton et al., 1995).

\section{MATERIALS AND METHODS}

Surgery, electrode assembly, and data acquisition. Surgeries were conducted according to National Institutes of Health guidelines for rodents. Eight male Fisher 344 rats were implanted under pentobarbital anesthesia with a "hyperdrive," a device holding a circular array of 14 separately movable microdrives. The construction of this device and the parallel recording technique were described in detail in Gothard et al. (1996). Briefly, each microdrive consisted of a drive screw coupled with a molded nut to a guide cannula. The guide cannula held a tetrode, a four-channel electrode constructed by twisting together four strands of polyimidecoated, $14 \mu \mathrm{m}$, nichrome wire (H. P. Reid, Neptune, NJ). A full turn of the screw advanced the tetrode $320 \mu \mathrm{m}$ into the brain. The stereotaxic coordinates for the placement of the electrode array were $2.5 \mathrm{~mm}$ lateral and $3.8 \mathrm{~mm}$ posterior to bregma on the right hemisphere. The tetrodes were lowered gradually into the CA1 layer of the right dorsal hippocampus. Two of the tetrodes served as reference and/or EEG electrodes, and the other 12 tetrodes were each connected to four separate channels of a multipin connector.

During training and recording, a headstage was attached to the multipin connector. The headstage consisted of two unity-gain, 25 channel, miniature FET preamplifiers (CFP-1020, Multichannel Concepts, Gaith- 


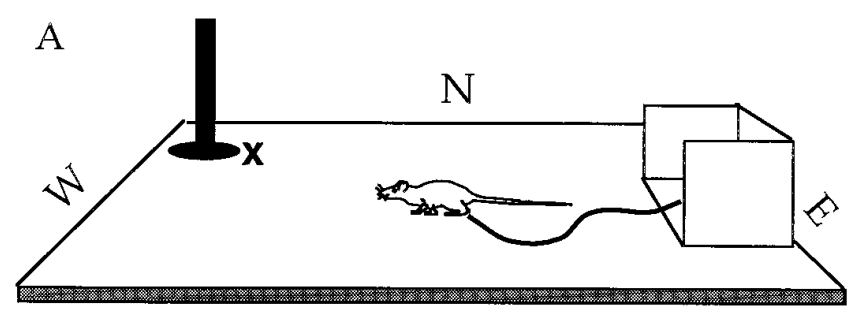

S

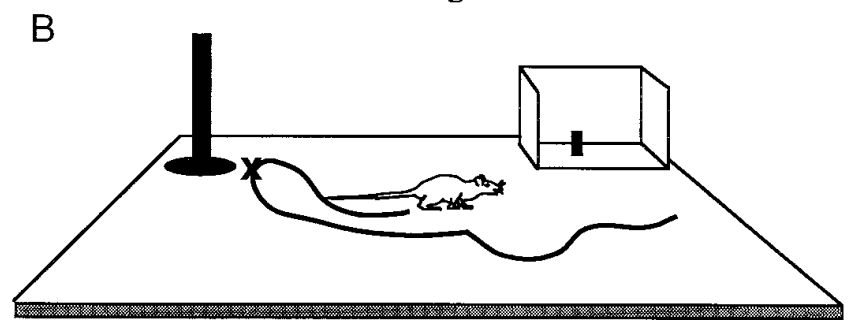

C

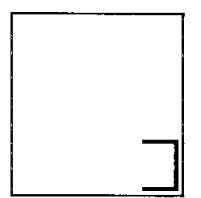

1

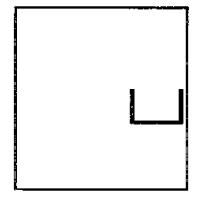

5

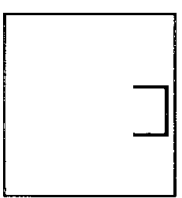

2

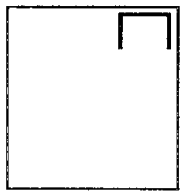

6

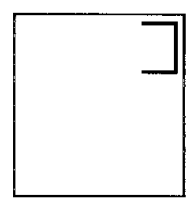

3

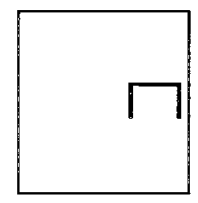

7

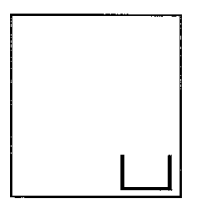

4

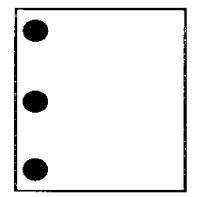

8
Figure 2. Behavioral apparatus for Experiment 2. A $1.2 \times 1.2 \mathrm{~m}$ platform was placed in the center of a room ( $3.5 \mathrm{~m}$ diameter area) surrounded by black curtains. Large white objects, serving as distal visual cues, were hung in front of the curtains (not shown). The box used in experiment 1 was also used in this task. A 5-cm-diameter, 40-cm-high landmark, which indicated the goal location $(x)$, was also placed on the platform. $A$, Outbound journey originating from the middle of the $E$ edge of the platform, with the box opening facing $W$. In this trial, the landmark was placed in the northwest corner of the platform. The place of the reward is indicated by the $x . B$, Inbound journey of the same trial. While the rat approached the landmark to eat the chocolate sprinkles placed near it, the box was moved to the NE corner of the platform and was rotated $90^{\circ}$ to face south. The following trial (data not shown) started from this box location. Computer software randomized box location, box orientation, and landmark location. $C$, Seven possible box locations and orientations (1-7) and three possible landmark locations $(8)$ were sampled with equal probability in each recording session.

ersburg, MD) and a $14 \mathrm{~cm}$ lightweight aluminum rod, reaching from above the head to the back, with a large cluster of infrared diodes in the front and a small cluster in the back. The front diodes generated a larger light spot than the back diodes, allowing a video tracking system (SA-2 Dragon tracker, Boulder, $\mathrm{CO}$ ) to record the position and head orientation of the animal with a sampling frequency of $20 \mathrm{~Hz}$.

A multiwire cable connected the headstage to a commutator (Beila Idea Development, Anaheim, CA) from which the signals were transmitted to an array of 56 digitally programmable amplifiers. The signals were amplified by a factor of 10,000 , bandpass-filtered between $600 \mathrm{~Hz}$ and 6 $\mathrm{KHz}$, and transmitted to an array of seven 80486 computers equipped with synchronized time-stamp clocks. The signals from each tetrode channel were digitized at $32 \mathrm{KHz}$. The relative amplitude of the spikes on different tetrode channels (McNaughton et al., 1983; Recce and O'Keefe,
1989) served as the basis for cell identification. Pyramidal cells were distinguished from interneurons based on spike width (spike width of at least $300 \mu \mathrm{sec}$ measured from peak to valley), the property of firing complex spikes, and an overall mean rate $<5 \mathrm{~Hz}$ during the recording session.

\section{Experiment 1}

Behavioral apparatus and training. The behavioral apparatus was a $188 \times$ $8 \mathrm{~cm}$ linear track placed across the corner of a large room and surrounded by the recording equipment and laboratory furniture. The recording area was illuminated by a surgical lamp that projected a bright light spot on one of the walls of the room. A $27-\mathrm{cm}$-high $\times 32$-cm-wide $\times 27$-cm-long sliding cardboard box, mounted on the track, could be moved quickly and easily to any of five equally spaced locations along the track (Fig. $1 A$ ). These five locations are henceforth referred to as box1, box2, box3, etc., with box1 being the location at one end of the track. A small food cup was mounted in the center of the carpeted floor of the box. A second food cup was affixed to the opposite end of the track. The distance from the front edge of the box to the fixed food cup varied from $161 \mathrm{~cm}$ for the longest journey to $53 \mathrm{~cm}$ for the shortest journey.

The task required the rats to run back and forth between the box and the fixed goal. While the rat was traveling from the box to the fixed goal, (outbound journey), the box was manually moved to one of the five possible box locations along the track. After visiting the fixed goal, the rat returned to the box, which was by then in a new location (inbound journey). This way, the position of the box was usually different at the beginning and end of a trial, and each trial started where the previous trial had ended. Custom-designed software controlled the randomization of box locations, ensuring that in a recording session (usually 75-100 trials), all five box locations were sampled equally. The first trial of each recording session started at box1 (the farthest from the fixed goal). Event flags, inserted automatically in the data file, marked the time of each box exit and box entry and also the time of reaching the fixed goal and departing from it. Event flags permitted the selection and analysis of all the outbound journeys that originated in any of the five box locations or the inbound journeys that ended in any box location (see Fig. 1B,C).

Training for this task started with 3-5 d of habituation to the apparatus. During this period, the rats were placed inside the box, which was always in position box1, and allowed to explore. Chocolate sprinkles were strewn along the track. After a few minutes of exploring the box, the rats started to explore the track and eat the chocolate. Initially, the rats made only short excursions from the box, but by the fifth day they ran the full length of the track without hesitation.

The initial experiences of all the animals on the track were with the box located at position box1. For six rats, recording started with the box fixed in this position, and the box was moved to new locations only after two to three recording sessions. For two rats, recording started after they had already experienced the box moving from trial to trial. Because no differences were observed in any of the analyses that could be attributed to these training procedure differences, the data from all rats were pooled.

To control for the occlusion of the distal visual cues by the walls of the box, an additional manipulation was performed in one rat. Halfway through the last recording session, the rat was briefly removed from the apparatus while the walls of the box were removed. The rat was then placed back on the remaining floor of the box and the recording was continued according to the normal protocol. With only the floor of the box left in place, the rat had full access to the distal visual cues.

Data analysis. The spatial firing profile for each cell was calculated by averaging the firing rates over all trials (15-20), for each type of outbound and inbound journey (e.g., box1-out, box2-out, box1-in, box2-in, etc.) (see Fig. 1). The firing profile is calculated as a function of position along the track, thereby ignoring any possible two-dimensional structure of the firing fields. To analyze the relative influences of the box or fixed spatial cues on place-cell firing, the firing profiles from the box1-out trials were compared with all the other firing profiles (box2-out, box3-out, etc.). The offset of the firing rate profile relative to the corresponding profile for the box1 position was estimated by calculating the spatial cross-correlation between the two rate distributions and measuring the spatial shift at which this function was maximal. This measurement took into account the shape of the firing profile, not merely the peak. Only points containing nonzero occupancies in both profiles were entered into the crosscorrelation. For each cell, the distance by which the profile shifted was plotted against the corresponding shift of the box relative to the position of box1, and a regression line was computed. The slope of the regression 
A Three consecutive trials on the track

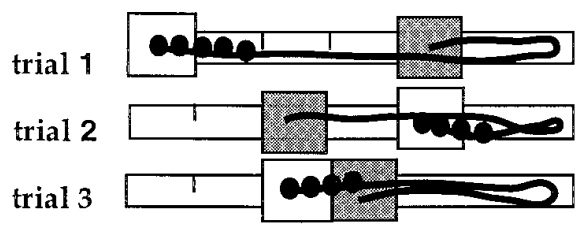

B Aligned in the start-box frame

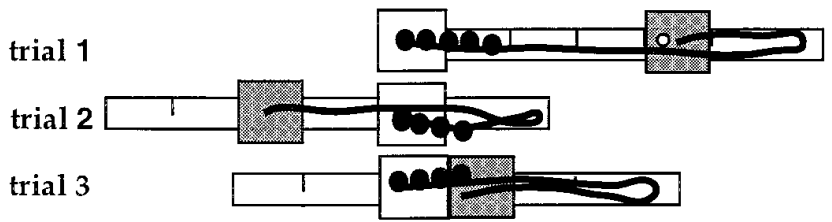

C Aligned in the end-box frame

trial 1

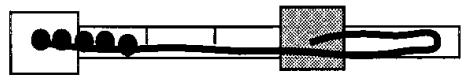

trial 2

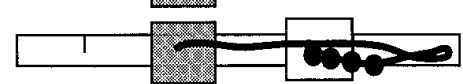

trial 3

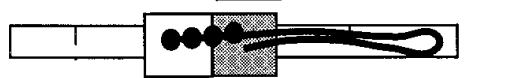

D Three consecutive trials on the platform

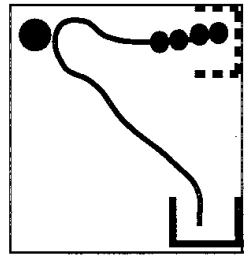

trial 1

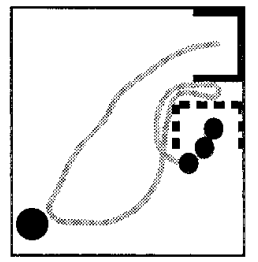

trial 2

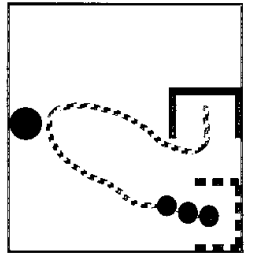

trial 3
E

$$
\begin{aligned}
& \text { Aligned in the } \\
& \text { start-box frame }
\end{aligned}
$$

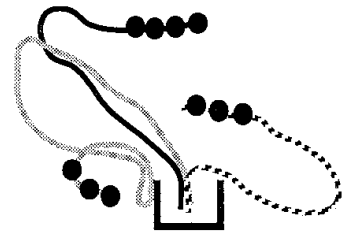

$\mathbf{F}$
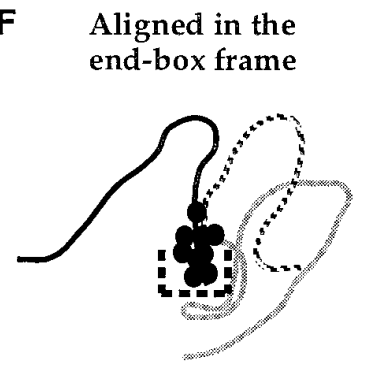

Figure 3. Schematic diagram showing three alignments used to analyze cell activity in both experiments. $A$, Three consecutive trials on the linear track. The open squares represent the location of the box at the start of a trial, whereas the gray squares represent the location of the box at the end of a trial. Note that the end-box position of the previous trial becomes the start-box position for the next trial. The black lines indicate the rat's trajectory, and the small back circles represent spikes fired by the cell. In this example, the cell fired each time the rat departed from the box. $B$, Each trial is shifted and aligned so that the white squares, representing the start-box locations, coincide. Note that, if the trials were superimposed, the spikes would form a single cluster. $C$, Each trial is shifted so that the end-box locations, represented by gray squares, coincide. This alignment generates multiple clusters of spikes when trials are superimposed. Thus, this idealized cell shows a single place field when the trials are aligned in the start-box frame but multiple place fields in the end-box and track frames. $D$, Three consecutive trials on the platform. The black, gray, and stippled lines represent the trajectory of the rat. The start-box location is indicated by the box drawn with solid lines, whereas the end-box location is drawn with dashed lines. The large black circle shows the position of the landmark in each trial, and the small black circles represent cell discharge. This idealized cell is active when the rat enters the box. E, The same three trials aligned and superimposed in the start-box frame. In this alignment, multiple clusters of spikes appear. $F$, The three trials aligned and superimposed in the end-box frame. This alignment gives rise to a single cluster of spikes. Thus, this cell shows a single place field when the trials are aligned in the end-box frame but multiple place fields in the start-box and platform frames.

line was normalized so that if the firing profile shifted by the same amount as the box, then the slope of the line, henceforth called displacement slope, would be 1.0 ; if the profile did not shift with the box, the displacement slope would be 0.0 . The slope could not be calculated if the cell did not fire for at least two different box locations. Figure $1, D$ and $E$, depicts two idealized cells with slopes of 1.0 and 0.0. The location of the peak firing on the full track was quantified on a scale from 0 to 1 , where 0.0 corresponded to the box 1 end of the track and 1.0 corresponded to the opposite end containing the fixed food cup.

Vector correlations were used to compare the population firing patterns at different points on the track, across different types of trials. Population vectors were constructed for each rat separately. For a given rat, all pyramidal cells with robust firing during any type of trial were used. Data from all available recording sessions were combined for this analysis, but if the same cell was recorded in multiple sessions, only data from one of these sessions were used. The full length of the track was divided into 64 equal bins, and the mean firing rate of each cell was calculated for each spatial bin for all 10 types of journeys. From these firing rates, an $n$-element population vector was constructed for each spatial location-trial type combination, where $n$ is the number of cells used from a rat. The correlation coefficient of each pair of population vectors was calculated and used as a measure of the similarity of population firing patterns at different locations on different types of trials.

To test whether cells whose spatial firing profiles overlapped on the shortened track were active simultaneously, we calculated the temporal cross-correlation between spike trains for a $1 \mathrm{sec}$ window with a $10 \mathrm{msec}$ bin size and also for a $200 \mathrm{msec}$ window with a $2 \mathrm{msec}$ bin size.

\section{Experiment 2}

Behavioral apparatus and training. Four of the eight rats involved in experiment 1 were trained for a second task. For this task, the box used in experiment 1 was moved to a new recording room, where it became part of a new behavioral apparatus. The new environment consisted of a $120 \times 120 \mathrm{~cm}$ wooden platform located on a table in the center of a $3.5 \mathrm{~m}$ diameter, curtained arena with numerous large visual cues at the periphery (Fig. 2). The room was illuminated by four symmetrical, mediumintensity lights. The rats were brought to this room without disorientation, and during training and recording, the door leading to the adjacent room with the recording equipment was left open.

The rats were trained to run back and forth for a small food reward between the box used previously on the track and a cylindrical landmark. The box could be placed at any of three equally spaced locations along the east edge of the platform, with the opening facing west, north, or south (see Fig. 2). The landmark could be placed at three equally spaced goal locations along the west edge of the platform. A trial consisted of an outbound journey, from the box to the cylindrical landmark, and an inbound journey, from the landmark back to the box. On each trial, a reward was placed on the platform adjacent to the landmark and in the food cup in the box. During the outbound journey, the box was moved to a new location and usually rotated $90^{\circ}$. Thus, the position and orientation of the box were always different at the beginning and end of a trial. While the rat was eating the reward inside the box, the landmark was placed in a new location so that consecutive trials had different goal locations. Custom-designed software controlled the randomization of box locations, 


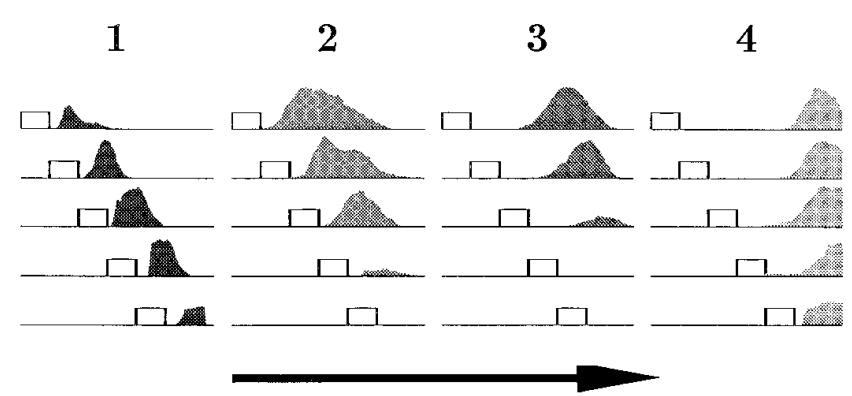

C

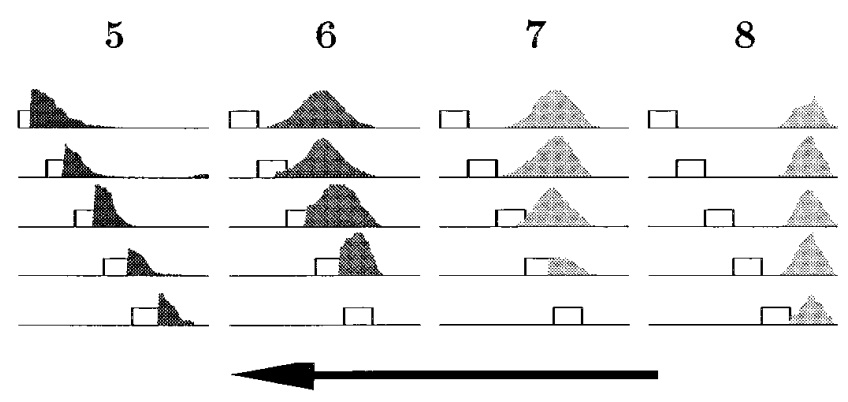

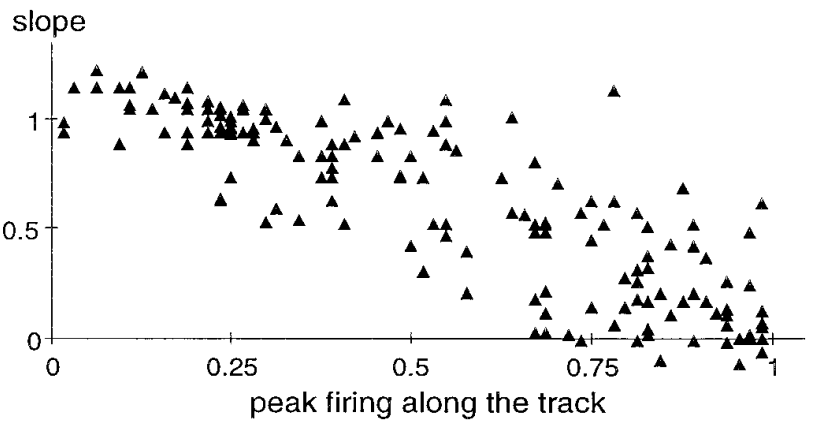

D

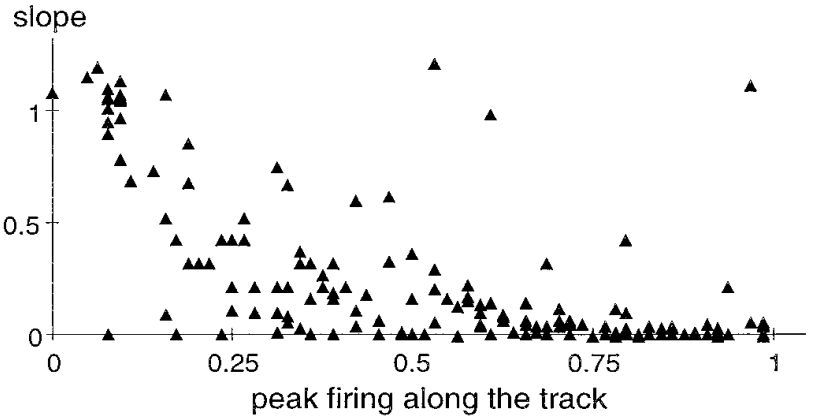

Figure 4. Relationship between spatial firing properties and box location for outbound and inbound journeys. $A$, Firing profiles of four outboundselective cells $(1,2,3,4)$ shown for all five types of outbound journey (see Fig. $1 B$ ). The horizontal lines represent the track, and the small rectangles represent the box. The last $27 \mathrm{~cm}$ portion of the track, containing the fixed reward cup, is omitted. Cell 1 fired immediately after the rat exited the box and had a displacement slope of 0.95; cell 2 fired farther away from the box and had a displacement slope of 0.72 ; cell 3 fired approximately halfway between the box and the goal and had a displacement slope of 0.57 ; cell 4 fired close to the goal and had a displacement slope of 0.10 . The maximum firing rates for cells $1,2,3$, and 4 were $11,30,18$, and $22 \mathrm{~Hz}$, respectively. Note that the firing field of cell 2 shrunk progressively as the box moved closer to the goal. Also, the firing rate of this cell was very low on box4-out trials and vanished on box5-out trials. Cell 3 showed decreased firing rates on box3-out trials and ceased firing on box4-out and box5-out trials. No such modulation of firing rate and firing field size were seen in cell 1 or cell 4 . $B$, Plot of the displacement slope as a function of the position of the peak firing along the track for box1-out trials (168 outbound-selective cells from eight rats). The horizontal axis represents the location of the peak firing on the track for the box1-out journeys and is scaled so that the origin corresponds to box1, and 1.0 corresponds to the fixed food cup. The vertical axis shows the displacement slope (ratio of the firing-field shift to the distance that the box was moved) representing the extent to which the box controlled cell activity. A displacement slope of 1 indicates that the cell fired at a fixed distance from the box across the five types of outbound journeys, whereas a displacement slope of 0 indicates that the cell fired at a fixed distance from the fixed reward site. This plot shows that all cells that fired on the initial part of the journey were strongly bound to the box. As the rat moved farther along the track, the displacement slope gradually declined. Near the end of the journey, the influence of the box was overridden by that of the fixed cues (displacement slope values near 0.0 ). Note that because a rat samples a limited region of the track on different journeys, certain combinations of slope versus peak firing along the full track are impossible. These lie at the bottom left and top right of plot B. C, Firing profiles of four inbound-selective cells $(5,6,7,8)$ shown for all five types of inbound journey (see Fig. $1 C$ ). Cell 8 fired immediately after the rat departed from the fixed site and had a displacement slope of 0.0 ; cell 7 fired farther away and had a displacement slope of 0.0; cell 6 fired approximately halfway between the fixed food cup and the box and had a displacement slope of 0.35 ; cell 5 fired as the rat was entering the box and had a displacement slope of 1.06. The maximum firing rates for cells 5, 6, 7, and 8 were 32 , 27, 21, and 11, respectively. Note that cells 6 and 7 ceased firing when the box was placed inside their firing fields. $D$, Plot of the displacement slope as a function of the position of the peak firing along the track for box1-in trials (157 inbound-selective cells from eight rats). More than half of the inbound trajectory was marked by firing fields at constant distances from the fixed reward site (displacement slopes close to 0.0 ). Cells with intermediate displacement slopes appeared only on the last part of the inbound journey and covered a shorter span of the inbound journey than cells with intermediate slopes did on the outbound journey. Box-related cells started to fire at a short distance before reaching the box and continued firing inside the box.

box orientations, and goal locations. The software inserted event flags into the data file, which marked the times of arrival at and departure from the box or the goal and position and orientation of the box for each exit and entry. Training for this task started when recording for experiment 1 was completed. Rats were considered ready for recording when they completed each trial in $<1 \mathrm{~min}$.

Each recording consisted of three sessions separated by 10-20 min breaks. The first session (30 min) was recorded on the linear track, the second session $(30 \mathrm{~min})$ on the platform, and the third session $(10 \mathrm{~min})$ on the linear track again. During the 20 min break between the sessions, the rat and the box were transported from one room to the other, and the cells were monitored while that rat was quietly resting to ascertain that no electrode drift had occurred in the previous session.
Data analysis. Only cells that showed the same spike shape and relative spike height on each of the four tetrode channels for each of the three recording sessions were included in the analysis. On the platform, the displacement slope could not be calculated, because the rat could run toward or away from the box in multiple directions. The alternative was to construct firing maps for each trial and to superimpose these maps in the absolute spatial frame of the environment or aligned on the box, either at the beginning or the end of each trial (Fig. 3 ). If a cell fired preferentially when the rat was inside the box, then a firing map for that cell in the absolute spatial frame would show five clusters of spikes, corresponding to the five possible box locations on the linear track, and three clusters for the corresponding box locations on the platform. When the same trials are aligned on the start- or 
1
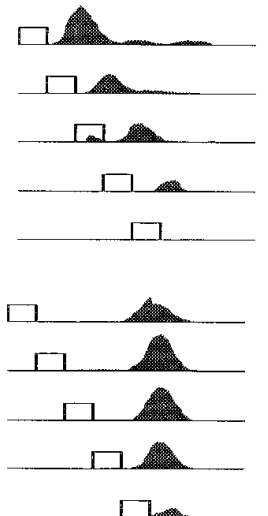

2
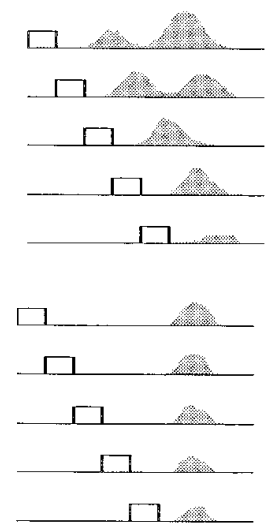

3
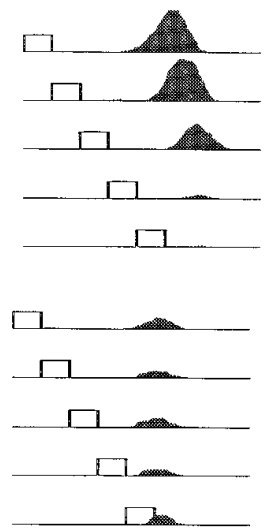

4
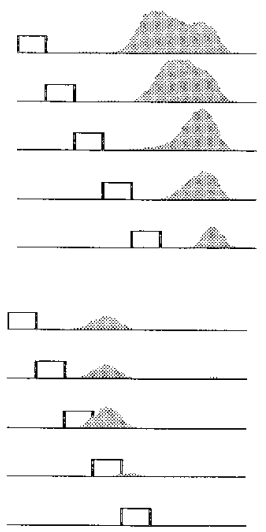

Figure 5. Examples of bidirectional cells. For each cell $(1,2,3,4)$, the top five plots represent the outbound journeys, and the bottom five plots represent the inbound journeys. Cell 1 , on the outbound journeys, fired shortly after the rat left the box; on the inbound journeys (below), this cell fired at a fixed location on the track, irrespective of box location. Cell 2, on the outbound journeys, fired at a constant distance from the box and showed two peaks of firing on the box1-out and box2-out journeys; on the inbound journeys, the firing field of this cell was stable with respect to the track. Cell 3, on the outbound journeys, fired nearer to the fixed site than to the box and, hence, had a small but positive displacement slope. On the inbound journeys, this cell had a place field at almost exactly the same location, but the displacement slope was 0.0 . Cell 4 , on the outbound journeys, showed a shrinking of the firing field and a progressive decline in firing rate; on the inbound journeys, the firing field was fixed with respect to the track. This figure illustrates that bidirectional cells share properties with the outbound-selective cells on the outbound journeys and with the inbound-selective cells on the inbound journeys. As in Figure 4, on both journeys the firing properties of the cells are determined primarily by the landmark of origin of the journey.

end-box frame, only one cluster of spikes would appear for both environments.

\section{RESULTS}

\section{Experiment 1}

The behavioral apparatus for Experiment 1 was the linear track. All eight rats trained on this apparatus acquired the task in six to seven training sessions. The rats were trained with the box always in position box1. They appeared to be startled and explored vigorously when they first encountered the box in an unexpected location. In the next two to three trials, however, they got used to the manipulation and showed no additional hesitation in entering the box.

The duration of a trial was $\sim 25 \mathrm{sec}$, including the time that the rat spent eating in the box and at the fixed food cup. Each rat adopted a stereotypical running and turning pattern inside the box and at the fixed food cup, and hence, at these points, only half of the possible head directions were sampled. In a recording session of 75 to 100 trials, each start-box and end-box location was sampled 15 to 20 times. The session came to an end when, because of fatigue or satiety, the rats slowed down, and the trial duration exceeded $45 \mathrm{sec}$.

From the 603 recorded cells that exhibited activity on the apparatus, 92 were interneurons (theta cells), and 511 were pyramidal (complex-spike) cells. Of the latter, 140 were eliminated from the main analysis for one of the following reasons: (1) the cell fired $<100$ spikes during the recording session (98 cells); (2) the cell fired on the whole length of the track in one direction but not in the other ( 7 cells); (3) the cell showed no consistent firing pattern (35 cells). Clear, location-specific firing was seen in 371 cells. The great majority of cells showed clear directional preferences: 157 cells were outbound-selective, 168 were inboundselective, and 46 fired in both directions. The distribution of place fields was uniform along the track, with no tendency to cluster at the reward sites. Because no recordings were made during sleep or quiet wakefulness, these numbers should not be taken as a measure of the probability that a given cell will be active in a given environment (Thompson and Best, 1989).

\section{Outbound-selective cells}

The outbound journey started when the rat finished eating the reward while facing the back wall of the box and turned to exit the box; the journey ended when the rat reached the fixed food cup at the opposite end of the track. Thus, some outbound cells fired inside the box and others on different portions of the track. The distribution of displacement slopes for the outbound-selective cells revealed that the extent to which the box or fixed cues influenced their firing on the shortened versions of the track was a function of the location of the place field on the full track (Fig. $4 A, B$ ). All cells active during the initial part of the outbound journey fired at fixed distances from the box, irrespective of box location, and hence had displacement slopes of 1 or close to 1 . (Recall that a slope of 1 indicated that the firing field shifted together with the box, whereas a slope of 0 indicated that the firing field was fixed relative to the track and the static background cues.) No cells with stable fields relative to the fixed cues were active inside or in the vicinity of the box, even though, after exiting the box, the external cues would presumably have been sufficient for the rat to determine its location on the track. Cells that fired farther from the box had intermediate displacement slopes. Cells showed stable firing fields with respect to the fixed cues (displacement slopes near 0 ) only when the rat reached the vicinity of the fixed reward site. The majority of the outbound-selective cells were influenced by the box; however, with increasing distance from the box, the displacement slopes gradually decreased, indicating that the influence of the box diminished, whereas that of the fixed cues gained strength (Fig. 4B).

With few exceptions, the outbound-selective cells that were active close to the box fired with comparable rates and for comparable spans of the rat's trajectory for all box locations. In contrast, the majority of cells with intermediate displacement slopes showed progressively decreasing firing-field size and decreasing mean firing rates from box1-out to box5-out runs. 
A OUTBOUND
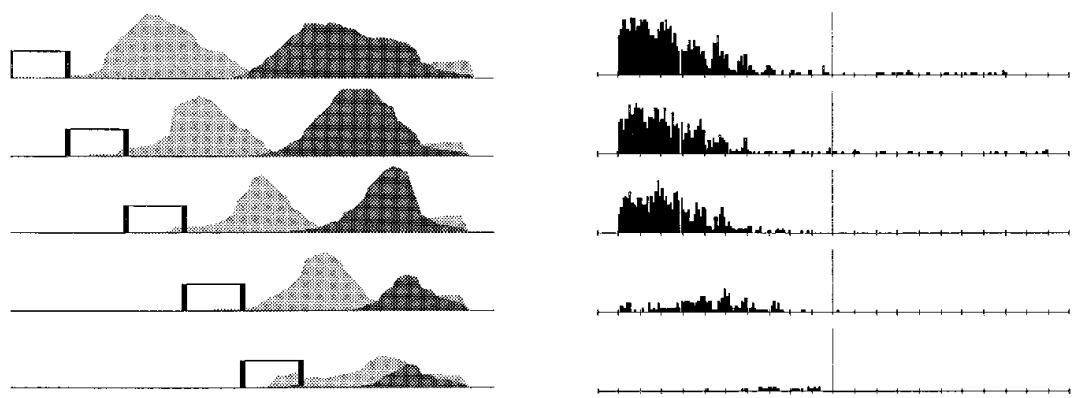

$-1$

1

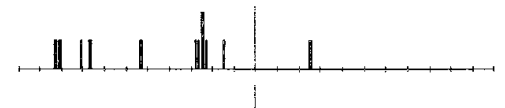

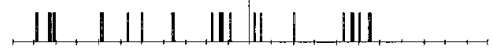

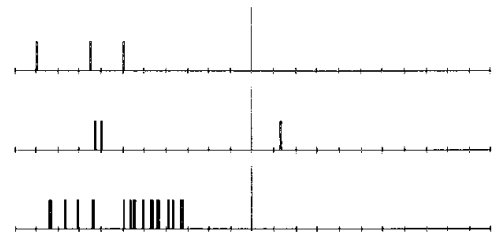

$-0.2$

0.2

\section{B OUTBOUND}
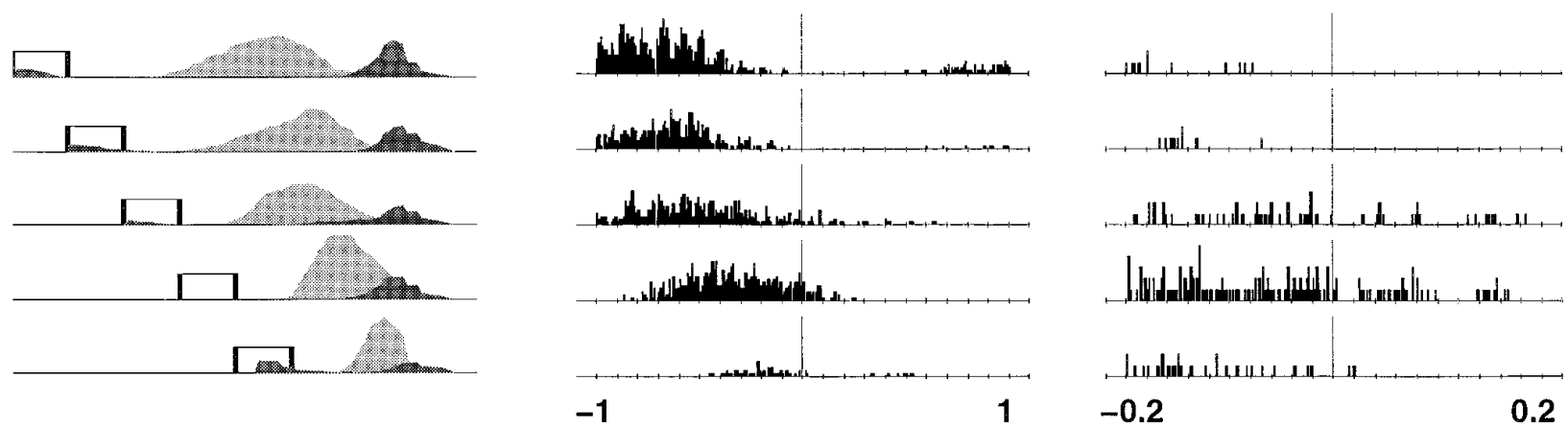

\section{INBOUND}
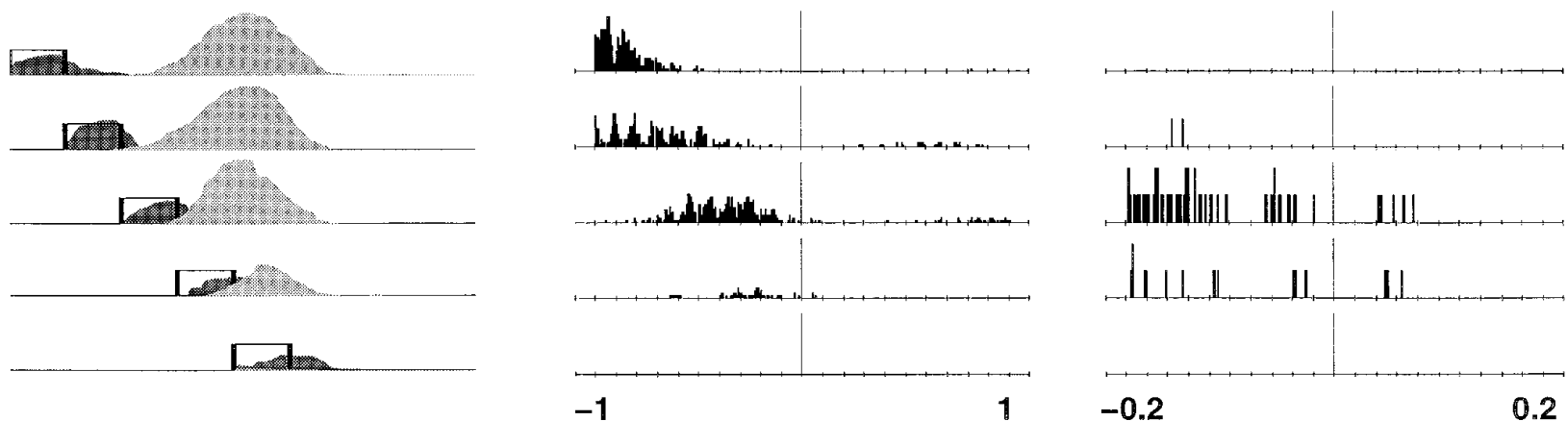

Figure 6. Temporal cross-correlations between cells with widely separated fields on the full track and adjacent or partially overlapping fields on the shortened track. Each row corresponds to a pair of simultaneously recorded cells. In each row, the first plot shows the firing profiles of the two cells (dark gray and light gray) on all five types of journeys. The middle plot shows the temporal cross-correlation ( $1 \mathrm{sec}$ window with $10 \mathrm{msec}$ bin size) between the two spike trains. The plots on the right show the same cross-correlation but for a window of $200 \mathrm{msec}$ with a bin size of $2 \mathrm{msec}$. $A$, Two outbound-selective cells with adjacent but nonoverlapping fields on the full track and partially overlapping fields on box5-out trials. The cross-correlations show no temporal overlap, although the fields appear to be spatially overlapping on the box5-out trials. Note that with increased distortion of the track, the sizes of the firing fields shrink, the centers of the fields converge, and the firing rates decline. $B$, Two outbound-selective cells with adjacent but nonoverlapping fields on the full track and partially overlapping fields on box4-out trials. This is an exceptional midtrack cell, because it fired on all five types of outbound journeys and increased its firing rate on box4-out and box5-out journeys. The cross-correlations for box1-out, box2-out, and box3-out trials show little or no temporal overlap. The cross-correlations for box4-out trials show some overlap but less than would be predicted from the spatial overlap of the firing profiles. $C$, Two inbound-selective cells with widely separated fields on the full track and partially overlapping fields on the box3-in and box4-in trials. The cross-correlations show little temporal overlap on these trials, although the firing profiles appear to overlap. Note that the second cell ceased firing on the box5-in trials.

[A few exceptional cells (13) increased their mean rates as the place field was compressed. Some of these cells fired only a few spikes on the full journey and, thus, appeared to be active only on shortened journeys.] Usually, on the shortest journey (box5out), only the cells with fields on the full track near the box or the fixed food cup remained active (e.g., cells 1 and 4, Fig. 4A), whereas cells with intervening fields were silent (e.g., cells 2 and 3, Fig. $4 A$ ).

\section{Inbound-selective cells}

The inbound journey started when the rat finished eating the reward at the fixed food cup and turned to proceed toward the 

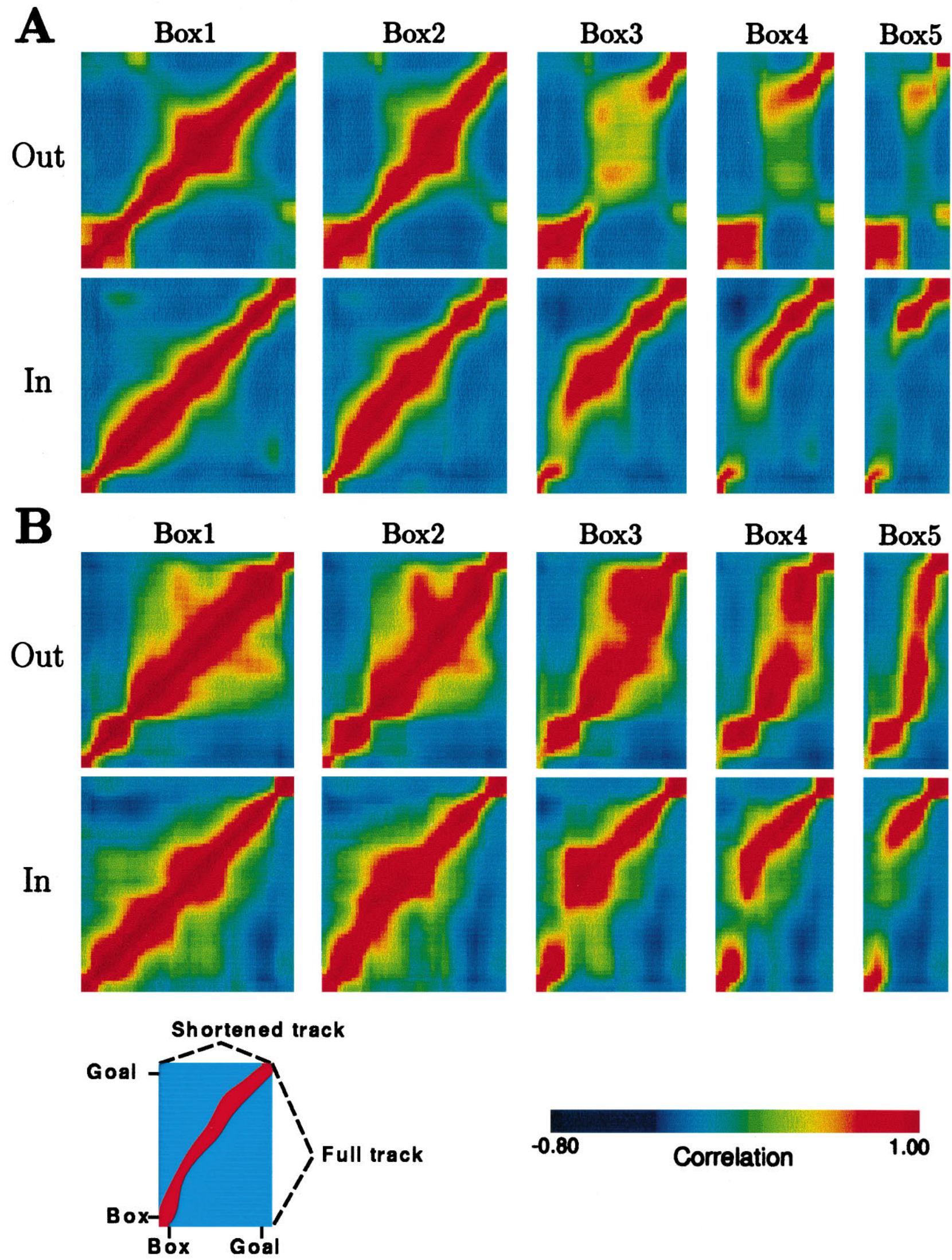

Figure 7. Population vector correlations between the pattern of firing on the full track and on the shortened track for two rats, A and B. For each rat, population vector correlations are shown for the outbound journeys (top five plots) and inbound journeys (bottom five plots). For each correlation plot, the vertical axis corresponds to the full track, whereas the horizontal axis corresponds to the length of the track covered by the rat in one of the five trial types (box1, box2, etc.; see Key, bottom left). Figure legend continues. 
box; the journey ended when the rat reached the food cup inside the box. A large fraction of inbound-selective cells had stable firing fields with respect to the fixed cues and, hence, had displacement slopes of 0 or close to 0 . Cells with displacement slopes approaching a value of 1 were seen only in the vicinity of the box. On the inbound journey, such cells started to fire only $5-10 \mathrm{~cm}$ before the rat reached the threshold of the box and continued to fire inside the box until the rat arrived at the food cup. Compared with the outbound journeys, a smaller fraction of cells had intermediate displacement slopes, and the transition from slope 0 to slope 1 was more abrupt (Fig. $4 B, D$ ).

Cells that fired in the vicinity of the fixed food cup, on either outbound or inbound journeys, had the same field size and firing rates for all types of journeys. Cells active in the middle part of the journey ceased firing when the box was placed over their firing field (Fig. 4C). To exclude the possibility that the lack of visual access to the fixed cues accounts for the cessation of firing, in the last recording session for one rat, the walls of the box were removed so that the rat was shuttling between the floor of the box and the fixed food cup. The floor of the box alone, placed in the firing field of an inbound-selective cell, was sufficient to inhibit its firing (data not shown). Moreover, this manipulation failed to introduce any detectable changes in cell activity.

Seven cells fired on the whole length of the inbound or the outbound journey but did not fire at all in the opposite direction. These cells did not show any particular characteristics that would differentiate them from ordinary complex-spike neurons.

\section{Bidirectional cells}

Forty-six cells $(12 \%)$ were bidirectional. Bidirectional cells fired on both the outbound and inbound journeys, but there was no apparent systematic relationship between the inbound and outbound firing locations. Typically, bidirectional cells behaved like outbound-selective cells on the outbound journey and like inbound-selective cells on the inbound journey (Fig. 5).

\section{Interactions between cells with neighboring place fields}

Spatial and temporal relationships between place fields were quantified in terms of cross-correlations between pairs of simultaneously recorded cells. All cell pairs showed a consistent order of cell firing on all types of journeys. The majority of cell pairs had nonoverlapping fields on the full track, which remained nonoverlapping on the shortened track. A few simultaneously recorded cells had partially or completely overlapping fields on the full track. The pattern of spatial overlap between cells with neighboring fields was altered when the journeys were shortened. Small distortions of the journey (e.g., box2-out) led to a proportional compression of the representation, indicated by reduced field size, converging field centers, and (on average) increased relative overlap between adjacent fields (Fig. 6A). Large distortions often led to the cessation of discharge in cells that were active in the middle of the journey, so that widely separated fields on the full track became adjacent or partially overlapping on the shortened track. Such pairs of cells were rare, even in data sets with 25 to 30 simultaneously recorded cells with clear fields on the full track. Figure 6 depicts three examples of these rare cases. The spatial overlap between firing profiles results partly from averaging data from multiple trials of the same type in which small, but coherent, shifts in the spatial distributions occurred between trials and partly from a true temporal overlap between the two spike trains within trials. The cross-correlations in Figure 6 show little overlap between cells with widely separated fields on the full track and spatially overlapping fields on the shortened track. The small overlap that occurred is restricted to $<\sim 250 \mathrm{msec}$ (1-2 theta cycles).

\section{Population properties}

The directional selectivity, together with the observation that bidirectional cells had unrelated discharge patterns on the outbound and inbound journeys, indicates that locations between the two reward sites on the full track were represented by uncorrelated distributions of place fields on the inward and outward journeys, with the same set of cells firing in the same order on each type of journey. Within each distribution, the relative firing times, times the rat's running velocity, corresponded to a metric for the length of the track. When the track was shortened, the first and last cells of the full sequence fired reliably, but the cells corresponding to the middle part of the journey showed dramatic changes. This effect was more pronounced on the outbound journeys. Cells corresponding to the middle part of the outbound journeys gradually decreased their firing rates and, often, the size of their firing fields, as the journey was shortened (see Fig. 4). Typically, on the shortest (i.e., box5-out) journeys, these cells stopped firing as if the population activation skipped the cells in the middle of the sequence. We tested the similarity of the population activation on the full-length journey and on the four types of shortened journeys by correlating point by point the population vectors computed for each spatial location (see Mate-

\footnotetext{
Highly correlated firing patterns between one location on the full track and a second location on one of the shortened tracks are indicated in red. The first plot in each row is a spatial autocorrelation of the population vectors on the full track, which gives rise to a perfectly symmetrical pattern, with values of 1.0 along the diagonal. The more similar the firing patterns on each shortened track to those on the full track, the more closely the correlation matrix for the shortened track resembles the autocorrelation. With few exceptions, the firing pattern at each location on each shortened track was very similar to the firing pattern of some location on the full track, as indicated by the red ridge of high correlation, either continuous or broken into two pieces. The exceptions correspond to locations where the ridge is discontinuous. The regions of the ridge corresponding to the box and to the fixed food cup always had high correlations. This indicates that the population firing pattern in the vicinity of the box and fixed food cup was always similar to the corresponding patterns on the full track. Thus, the pattern of high correlation points gives a picture of the "mapping" from the shortened track to the full track (also shown in Fig. 8). A, Population vector correlations for rat A (78 cells). For both outbound and inbound journeys, the pattern of activity on the full track was highly correlated with the pattern of activity on the box2-out and box2-in trials. The correlation matrix was similar to the autocorrelation but exhibited a slight deviation from the diagonal. This deviation indicates that on box 2 trials, the population activity pattern was governed primarily by the origin of the journey at early times and by the destination of the journey at later times. Beginning with the third plot (box3-out and box3-in trials), the correlation matrix shows striking differences from the autocorrelation matrix. When the track was greatly shortened, e.g., on the box4-out trials (fourth plot to the right), the pattern of activity remained correlated at the beginning of the trial when the rat is in the vicinity of the box. Then there is an area of low correlation and a sudden jump to the final part of the journey, where the activity patterns are highly correlated again, indicating that there is a discontinuous shift in the representation. $B$, Population vector correlations for rat B ( 35 cells). The same general features as for rat A are apparent, except for the correlation pattern for the shortened outbound journeys (top row). In contrast to the other seven rats, this rat showed continuous transition of the representation on all the outbound journeys. The population vector correlations on the inbound journey show discontinuity. This indicates individual differences between rats in the way the representation responds to shortening of the track.
} 

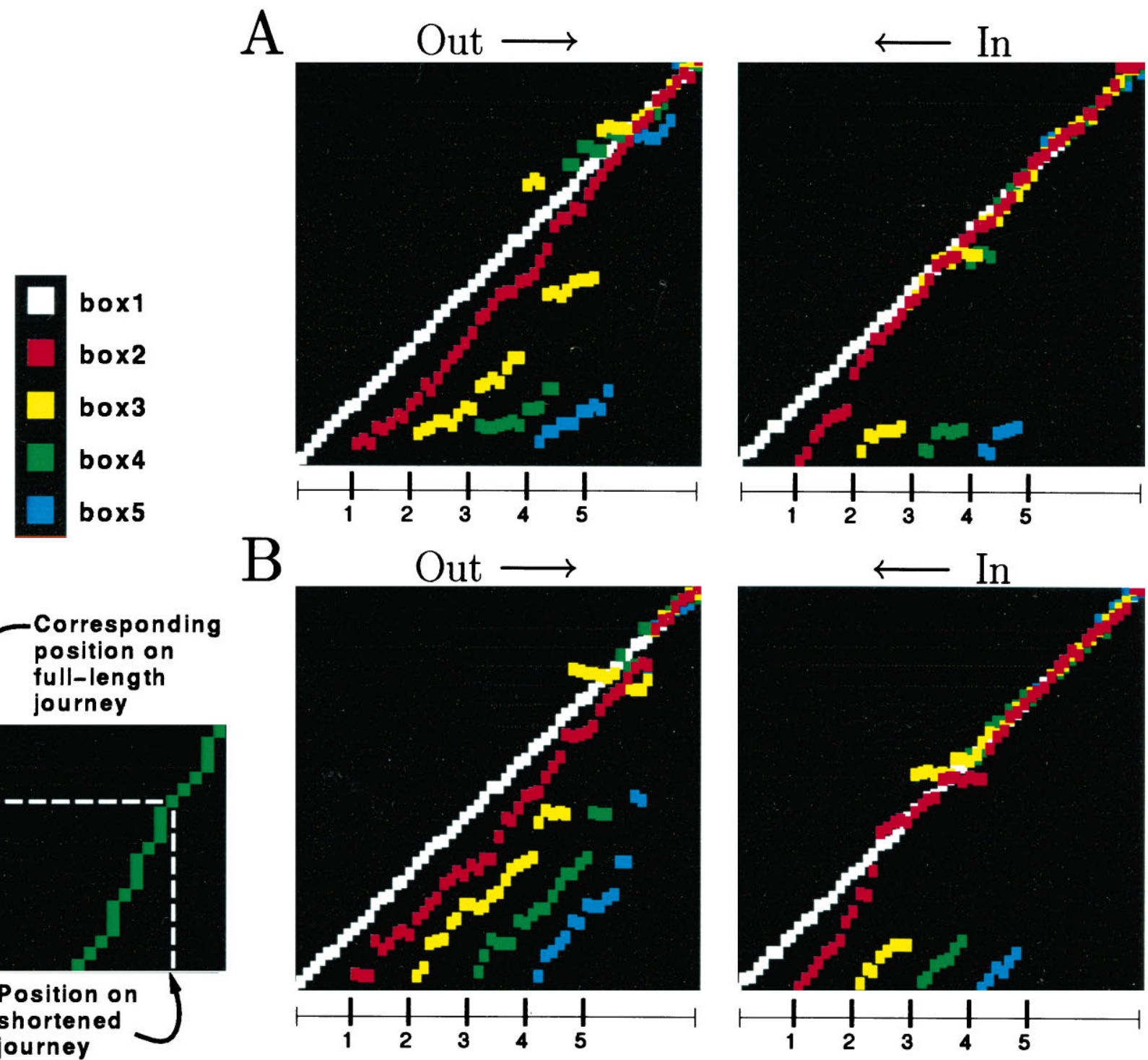

Figure 8. Mappings from each shortened track to the full track, derived from the correlation plots shown in Figure 7 for rats A and B. Each black panel shows five superimposed plots, color-coded according to the box location (see Key at bottom left). For each rat, the left panel shows mappings for the outbound journeys, and the right panel shows mappings for the inbound journeys. A schematic outline of the track is drawn at the bottom of each panel, where 1-5 indicate the front edge of the box. As illustrated in the key (top left) each curve shows for every point on one of the shortened journeys the point on the full journey where the hippocampal representation was most similar. In other words, the colored points correspond to the red ridges of the correlations plots in Figure 7. In each plot, the white dots aligned along the diagonal represent the identity mapping, associating the box1 journeys with themselves. In all cases, the red dots, representing box 2 journeys, form a continuous, slightly curved line indicating a gradual transition of the representation between origin and destination. Most of the other plots, corresponding to shorter journeys, show discontinuities at some point along the journey, indicating abrupt shifts in the hippocampal representation. Note that the length of the segments in which the colored plots are parallel to the identity line reflects the distance over which the representation was dominated by the box. For some outward journeys, this was almost $1 \mathrm{~m}$, even though the box was behind the rat, outside of its field of view. In contrast, for inbound journeys, the representation did not become dominated by the box until the rat was within $\sim 20 \mathrm{~cm}$.

rials and Methods). As seen in Figure 7, for most points on the shortened journeys, there was a unique region of high correlation on the full track (red ridge in the figure). The location of the high correlation areas shows that the population firing patterns in the vicinity of the box and fixed food cup were always similar regardless of the box location.

The point of maximal population vector correlation provides a function relating the representation of the shortened track to that of the full track (Fig. 8). This operation is equivalent to reconstructing the rat's virtual location on the full track from the activity recorded on the shortened tracks, according the method of Wilson and McNaughton (1993). For all configurations, the slope of this function was parallel to the slope of the identity mapping at the beginning and end of the journey and steeper in the intervening regions; the shorter the journey, the greater the intervening slope. For the most compressed configurations, there was almost always a discontinuity, indicating an abrupt jump from one hippocampal representation to another, without passing through the intervening states. There were individual differences among rats as to whether and where these transitions occurred. For one exceptional rat, the transition appeared to remain continuous for all outbound journeys; however, it was discontinuous 
on the inbound journeys (Fig. $7 B$ ). For all rats, on the inbound journeys, the transition occurred a short distance before the rat crossed the threshold of the box. For the outbound journeys, however, the transition usually occurred midway between the box and the fixed reward site. Thus, the hippocampal representation remained aligned with the box for almost half of the outbound journey. This is an important observation, because the box was at this time behind the rat and, thus, outside its field of view.

Cells recorded on the same tetrode did not usually have adjacent firing fields. It was common, however, to find cells with very similar firing correlates recorded in the same session from different tetrodes. When one cell with a well-characterized behavioral correlate did not fire on one trial or fired in an unexpected location, simultaneously recorded cells with similar correlates showed the same behavior. This indicates a strong functional coupling between cells with similar place fields.

\section{Experiment 2}

Experiment 2 was designed to test whether cells that fired as the rat entered or exited the box retained this behavioral correlate in a second environment. Although the four rats involved in this experiment learned in four to six training sessions to exit the box, orient toward the landmark, and return to the box after consuming the reward, they occasionally encountered difficulty finding the entrance side of the box. (Recall that while the rat was traveling toward the landmark, the box was moved to a new location and rotated so that the entrance was facing a new direction.) As illustrated in Figure $3 D$, they often walked along the walls of the box searching for the entrance. A total of 122 cells, with activity in one or both of the environments, were recorded from four rats. Of these, 73 were active both on the linear track and the platform, 18 were active only on the linear track, and 31 cells were active only on the platform. If a cell fired as the rat was either entering or exiting the box, or when it was inside the box, the cell was considered box-related. Only 8 of 27 cells that were box-related on the track were box-related on the platform too, indicating that neither the sensory features of the box nor the behavior of entering or exiting it were enough to account for the cell's activity. Even these eight cells were box-related in different ways, e.g., a box-outward cell on the linear track fired inside the box on the platform. In addition to the eight cells that were box-related in both environments, five cells fired in relation to the box on the platform but were silent on the track. Despite the common physical element between the two environments (the box) and the common element between the tasks (shuttling between box and a goal), the firing correlate on the track did not predict the firing correlate on the platform or vice versa (Fig. 9).

\section{DISCUSSION}

Experiment 1 examined the place fields of hippocampal cells in rats that had been trained to shuttle on a track between a box at one end and a fixed reward site at the opposite end. During recording, the box was shifted from trial to trial to different locations on the track, thereby creating mismatches with the originally learned relationships of the box to other cues in the environment. Along a journey, the same cells were active, in the same order, regardless of the location of the box, although elements of the sequence of place fields on the full track were sometimes omitted. Despite the constancy of the order, the specific locations of the firing fields shifted in a systematic and predictable way as a function of box location. These facts permit- ted the use of a population vector analysis to construct a "mapping" from each shortened track to the full-length track.

The principal finding was that when a mismatch existed between the internal spatial representation and real-world coordinates, defined by external cues, this led to a dynamic correction process. For small mismatches, the internal representation, after an initial delay, was translated smoothly through intervening states, faster than the animal's actual speed, until the internal representation "caught up" with the real-world coordinate. In case of large mismatches, however, one internal representation collapsed and the other representation emerged in its place, and the intervening coordinates were skipped. For intermediate mismatches, a combination of these effects was observed. This description is derived from the variation of the displacement slope as a function of the location of a firing field on the full track (Fig. 4), from the compression of place fields and reduction in firing rate for cells with intermediate displacement slopes during intermediate compressions (i.e., box 2 and box 3 ), and from the disappearance of some midtrack fields in the highly compressed configurations (i.e., box4 and box5).

An important conclusion can be drawn from the delay in the correction of the internal representation on outbound journeys. This delay implies that during the first $\sim 50 \mathrm{~cm}$, the rats updated their internal representations primarily with respect to their distance from the box, even though the only external landmark that might serve to anchor the representations was the box itself, which was behind the rat, presumably outside of its field of view. This indicates that during this time, the position representation was updated on the basis of path integration in spite of the mismatch with the external visual cues. This conclusion is reinforced by the observation that on inbound journeys, even though the rat was facing the box, the correction of the mismatch did not begin until the rat was within $10-15 \mathrm{~cm}$ of the box. The ability of rodents to update their position representation on the basis of self-motion cues has been demonstrated directly by behavioral experiments (O'Keefe, 1976; Mittelstaedt and Mittelstaedt, 1982; Cheng, 1986; Etienne et al., 1986; Sharp et al., 1990; Etienne, 1992; Seguinot et al., 1993; Knierim et al., 1995; Alyan, 1996). Several theoretical models have attempted to account for this phenomenon (Worden, 1992; Wan et al., 1994; Maurer and Seguinot, 1995; Redish and Touretzky, 1996; McNaughton et al., 1996).

Thus, it appears that both path integration and external sensory information interact to update the rat's location representation. The delay in correcting the representation in cases of mismatch suggests that the path integration mechanism normally dominates the update process and indeed may provide the fundamental spatial metric for the map (O'Keefe and Nadel, 1978; McNaughton et al., 1996). This is consistent with previous observations on the behavior of place and head direction cells in a cylindrical apparatus after cue rotation (Knierim et al., 1995). In that study, mismatches between the internal angular representation and the actual directional cues were often corrected only after a delay and, in some cases, not at all. When corrections occurred, they were usually continuous, as was the case for the linear coordinate during small distortions in the present study.

The results of the present work and of an earlier study (Gothard et al., 1996), in which rats shuttled between a box and a pair of landmarks placed variably in a large arena, are consistent with the idea that place fields are controlled by a competitive interaction between path integration and external sensory input, primarily vision. The neural substrate of this interaction is not yet understood, but the essential information is available to the hip- 
A
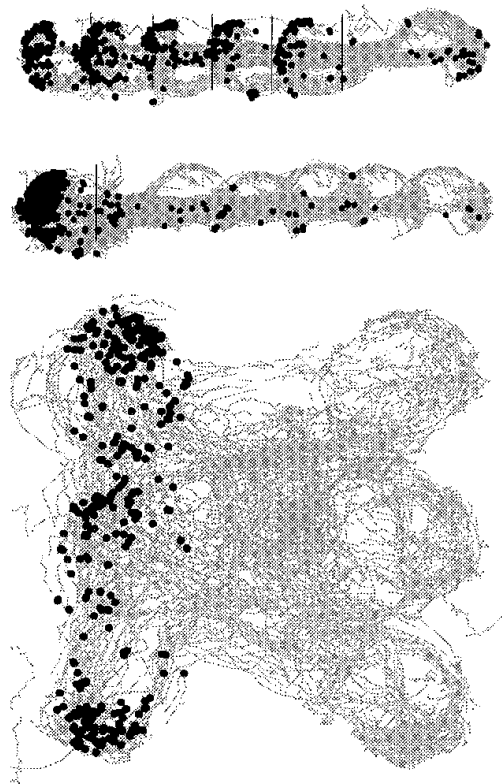

D
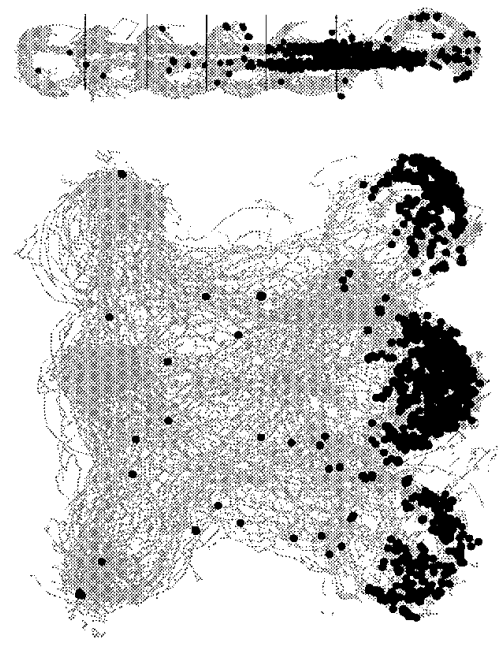

B
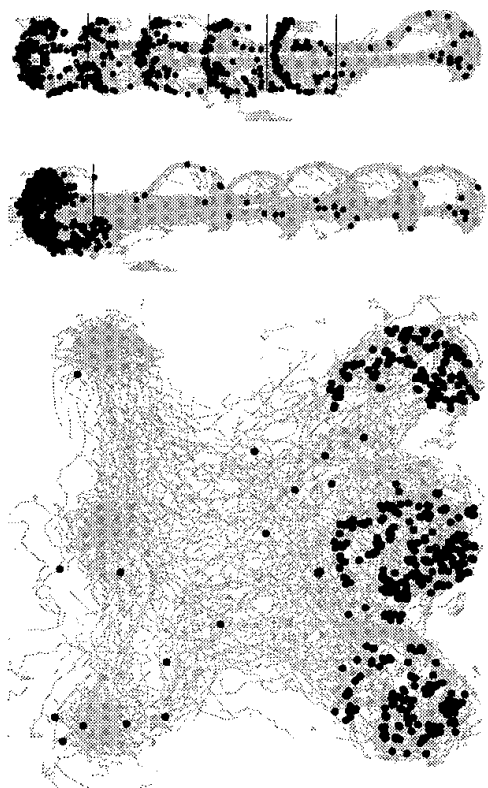

E
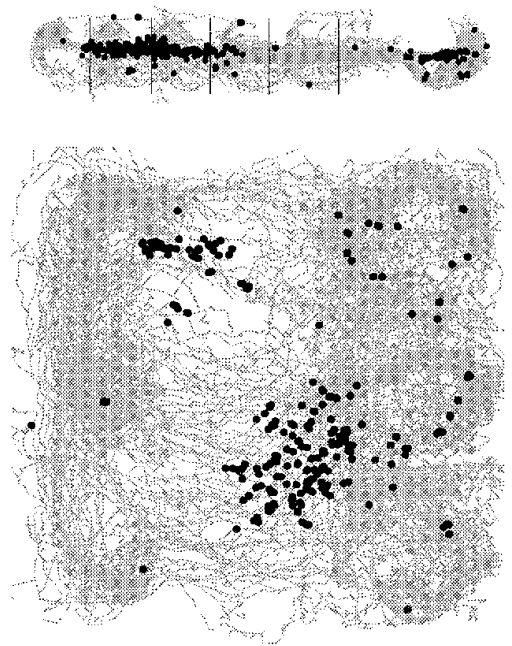

$\mathrm{C}$
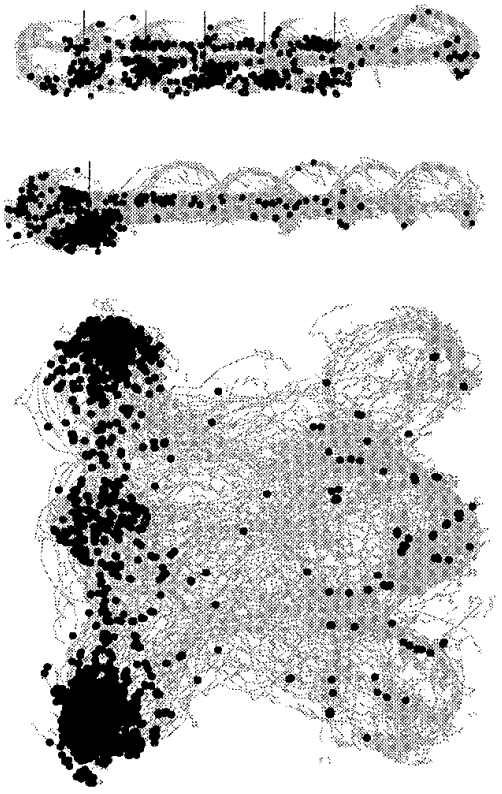

$\mathbf{F}$
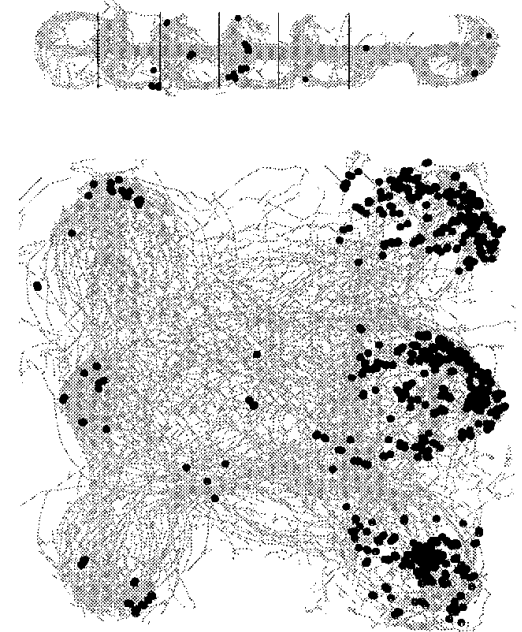

Figure 9. Examples of cells recorded both on the linear track (Experiment 1) and on the square platform (Experiment 2). Each plot is a spatial firing map in which the gray lines represent the superimposed trajectories of the rat, and the black circles represent cell discharge. For the first three cells $(A$, $B, C)$, the top panels depict the firing map on the linear track obtained by superimposing all the trials, the panel below shows the same trials aligned and superimposed in the box frame (see Materials and Methods) (see Fig. 3), and the bottom panel shows the firing map for the same cell on the square platform. For cells $D, E$, and $F$, only two firing maps are shown. The fine vertical lines on the linear track correspond to the front of the five box locations. In the panels depicting the square platform, the box and goal locations correspond to three equidistant locations along the left and right edge, respectively (see Materials and Methods) (see Fig. 2). A, A cell that fired inside the box on the track and in the vicinity of the landmarks on the platform. The top panel shows that the cell fired preferentially in five equally spaced locations corresponding to the five box locations on the track. When the trials are aligned and superimposed so that the box locations coincide (below), a single cluster of firing appears, indicating that this cell fired specifically when the rat was inside the box. On the platform, the cell fired exclusively when the rat was at the three landmark (goal) locations. $B$, A cell that fired inside the box both on the track and on the platform. The three clusters of spikes on the right edge of the platform indicate that the cell fired on the platform when the rat was inside the box. $C$, This cell fired on the track just as the rat was leaving the box, and it showed very strong activity near the landmark in all three landmark locations on the platform. The trials in the middle panel are aligned on the start-box frame to show that the firing field spans the threshold of the box, indicated by a thin vertical line. $D$, This cell had a bidirectional place field on the track and strong fields inside the box on the platform. In the top panel, the bottom streak of spikes corresponds to the outbound journeys and the top streak to the inbound journeys. A bidirectional cell of this type is shown in Figure 5, cell 1.E, This cell had an inbound-selective place field on the track and a nondirectional place field on the platform. A second field is suggested by the small cluster of spikes near the top left corner of the platform. $F$, This cell was silent on the linear track but fired reliably on the platform when the rat was turning from the food cup, ready to exit the box. In general, there was no consistent relationship of cells to the box across different environments. 
pocampal formation. External visual information is conveyed to the hippocampal formation via the ventral (inferotemporal) visual processing stream (Ungerleider and Mishkin, 1982). Information about head direction is available in at least two parts of the hippocampal system, the postsubiculum and the anterior thalamus (Taube et al., 1990; Taube, 1995). Finally, information about self-motion is also available from cingulate and posterior parietal cortices (Chen et al., 1994) and possibly also from the medial septum (Ranck, 1973).

The plots in Figure 4, $B$ and $D$, are reminiscent of a hysteresis loop, suggesting that the place-cell activity pattern at any moment is determined primarily by the previous activity pattern and not by the incoming sensory information. Together with the continuous corrections for small mismatches, this provides compelling evidence that internal representations of position are stabilized by cooperative intrinsic interactions and are not merely driven by the current exteroceptive input (Tsodyks and Sejnowski, 1995; McNaughton et al., 1996).

The emergence of a place field map in the dark and its persistence when lights are turned on (Quirk et al., 1990) suggest that the position representations themselves are either preconfigured within the connections of the network or developed as a consequence of path integration. Thus, the metric for the location representation appears not to derive from the perception of spatial relationships, such as the geometry of the environment, visual angles, and retinal image sizes of landmarks, but rather from self-motion cues.

The role of path integration in updating the hippocampal spatial representation offers an explanation for recent results of O'Keefe and Burgess (1996) on stretching and doubling of place fields when the size and/or aspect ratio of a rectangular recording box were altered. In that study, the rats foraged randomly in a two-dimensional space and, hence, would be expected to show nondirectional place fields (Muller et al., 1994; Markus et al., 1995). When place fields split or elongated as a consequence of stretching the environment, the two half fields were almost always directionally selective. The directionality of the firing in the two half fields was typically oriented toward the center of the field, indicating that the wall behind the rat was the main predictor of where the cell would fire. This form of directional selectivity can be explained by the assumption that the rats take position fixes when they are at or very near the walls and then update their position representation primarily by path integration as the they move away from the walls. If this account is correct, then the splitting of place fields in the O'Keefe and Burgess study results from the same kind of hysteresis that caused the delay in mismatch correction in the present experiments. O'Keefe and Burgess accounted for this effect by a Gaussian influence of the walls on the firing of place fields at a given position. The present results suggest that the determinant is primarily the activity of the cells, the place fields of which were most recently traversed, coupled with direction and linear motion information. The walls may initiate the sequence, but there is no direct influence of the walls per se.

Experiment 2 was designed to determine whether cells that fire in or near the box represent sensory qualities of the box, reward contingencies, or the behaviors of entering or exiting the box. If any of these possibilities were true, cells should have maintained their firing correlate in relation to the box, even when the box was in a new spatial context. In this experiment, most cells that fired in or near the box in one of the two environments (track or platform) failed to show box-related activity in the other environment.
These results show that box-related cells are not simply "box detectors"; instead they behave as place cells in other studies with recordings in multiple environments (Kubie and Ranck, 1983). Feature-selective responses are more common for entorhinal cortical cells, as shown by Quirk et al. (1992), who found that entorhinal input cells were significantly more driven by the sensory features of the environment than CA1 place cells. CA 1 cells appear to be governed more by cooperative, intrinsic dynamics than by a predominance of strong, feature-selective inputs to individual place cells.

In a previous study (Gothard et al., 1996), we showed that place cells can be bound to different behaviorally relevant, variably placed landmarks in an environment and interpreted this as evidence that the hippocampus encodes location within multiple, landmark-centered, spatial reference frames, where the term "reference frame" was intended to be synonymous with a map-like representation encoded in a specific distribution of place fields (Gothard et al., 1996) (see also Wan et al., 1994). In this interpretation, reference frame shifts would be equivalent to the rearrangement of place fields that occurs across different environments. In light of the present results, however, it appears that landmark-bound firing is attributable to a mismatch correction within a single map rather than to a switching of maps. Thus, at least under the present conditions, a journey between two points seems to be encoded on a single map rather than on a mosaic of different maps. Shifts of reference frame do seem to occur, however, if one redefines reference frame to be a given object or set of objects in relation to which location is encoded. Shifts of maps do occur between environments as well as between inward and outward journeys on linear tracks (McNaughton et al., 1989; Wan et al., 1994) or when task demands change (Markus et al., 1995). On linear tracks, map-shifts can account for place-cell directionality.

Finally, the present results may provide insight into general brain mechanisms involved in updating and correcting conflicts between internal models of the world and external sensory input.

\section{REFERENCES}

Alyan SH (1996) Evidence for resetting the directional component of path integration in the house mouse (mus musculus). Ethology 102:629-638.

Barnes CA (1988) Spatial learning and memory processes: the search for their neurobiological mechanisms in the rat. Trends Neurosci 11:163-169.

Breese CR, Hampson RE, Deadwyler SA (1989) Hippocampal place cells: stereotypy and plasticity. J Neurosci 9:1097-1111.

Chen LL, Lin L-H, Barnes CA, McNaughton BL (1994) Head-direction cells in rat posterior cortex. II. Contributions of visual and ideothetic information to the directional firing. Exp Brain Res 101:24-34.

Cheng K (1986) A purely geometric model in the rat's spatial representation. Cognition 23:149-178.

Eichenbaum H, Cohen NJ (1988) Representation in the hippocampus: what do hippocampal neurons code? Trends Neurosci 116:244-248.

Eichenbaum H, Kuperstein M, Fagan A, Nagode J (1987) Cue-sampling and goal-approach correlates of hippocampal unit activity in rats performing an odor-discrimination task. J Neurosci 7:716-732.

Eichenbaum H, Wiener SI, Shapiro ML, Cohen NJ (1989) The organization of spatial coding in the hippocampus: a study of neural ensemble activity. J Neurosci 9:2764-2775.

Etienne AS (1992) Navigation of a small mammal by dead reckoning and local cues. Curr Dir Psychol Sci 1:48-52.

Etienne AS, Maurer R, Saucy F, Teroni E (1986) Short-distance homing in the golden hamster after a passive outward journey. Animal Behav 34:696-715.

Fukuda M, Kobayashi T, Ono T, Tamura R (1992) Effects of learning place significance in rat hippocampal place cells. Soc Neurosci Abstr 18:1426. 
Gothard KM, Skaggs WE, McNaughton BL (1995) Interactions between multiple spatial reference frames in the rat hippocampus. Soc Neurosci Abstr 21:941.

Gothard KM, Skaggs WE, Moore KM, McNaughton BL (1996) Binding of hippocampal CA1 neural activity to multiple reference frames in a landmark-based navigation task. J Neurosci 16:823-835.

Hampson RE, Heyser CJ, Deadwyler SA (1993) Hippocampal cell firing correlates of delayed-match-to-sample performance in the rat. Behav Neurosci 107:715-739.

Jarrard EL (1993) On the role of the hippocampus in learning and memory in the rat. Behav Neural Biol 60:9-26.

Jung MW, McNaughton BL (1993) Spatial selectivity of unit activity in the hippocampal granular layer. Hippocampus 3:165-182.

Knierim JJ, Kudrimoti HS, McNaughton BL (1995) Place cells, head direction cells, and learning of landmark stability. J Neurosci 15:1648-1659.

Korshunov VA, Wiener SI, Korshunova TA, Berthoz A (1996) Placeand behavior-independent sensory triggered discharges in rat hippocampal CA1 complex spike cells. Exp Brain Res 109:169-173.

Kubie JL, Ranck Jr JB (1983) Sensory-behavioral correlates in individual hippocampal neurons in three situations: space and context. In: Neurobiology of the hippocampus (Seifert W, ed), pp 433-447. London: Academic.

Markus EJ, Barnes CA, McNaughton BL, Gladden VL, Skaggs WE (1994) Spatial information content and reliability of hippocampal CA1 neurons: effects of visual input. Hippocampus 4:410-421.

Markus EJ, Qin Y, Leonard B, Skaggs WE, McNaughton BL, Barnes CA (1995) Interactions between location and task affect the spatial and directional firing of hippocampal neurons. J Neurosci 15:7079-7094.

Maurer R, Seguinot V (1995) What is modeling for? A critical review of models of path integration. J Theor Biol 175:457-475.

McNaughton BL, Barnes CA, O'Keefe J (1983) The contributions of position, direction, and velocity to single unit activity in the hippocampus of freely-moving rats. Exp Brain Res 53:41-49.

McNaughton BL, Gothard KM, Skaggs WE (1995) Context-dependent binding of hippocampal "place cells" to different feature-centered reference frames. Soc Neurosci Abstr 21:941.

McNaughton BL, Barnes CA, Gerrard JL, Gothard KM, Jung MW, Knierim JJ, Kudrimoti HS, Qin Y, Skaggs WE, Suster M, Weaver KL (1996) Deciphering the hippocampal polyglot: the hippocampus as a path integration system. J Exp Biol 199:173-185.

Mittelstaedt H, Mittelstaedt ML (1982) Homing by path integration. In: Avian navigation (Papi H, Wallraff G, eds), pp 290-297. Berlin: Springer.

Muller RU, Kubie JL (1987) The effects of changes in the environment on the spatial firing of hippocampal complex-spike cells. J Neurosci 7:1951-1968.

Muller RU, Kubie JL, Ranck Jr JB (1987) Spatial firing patterns of hippocampal complex-spike cells in a fixed environment. J Neurosci 7:1935-1950

Muller RU, Bostock E, Taube JS, Kubie JL (1994) On the directional firing properties of hippocampal place cells. J Neurosci 14:7235-7251.

O'Keefe J (1976) Place units in the hippocampus of the freely moving rat. Exp Neurol 51:87-109.

O'Keefe J, Burgess N (1996) Geometric determinants of the place fields of hippocampal neurones. Nature 381:425-428.
O'Keefe J, Conway DH (1978) Hippocampal place units in the freely moving rat: why they fire where they fire. Exp Brain Res 31:573-590.

O'Keefe J, Dostrovsky J (1971) The hippocampus as a spatial map. Preliminary evidence from unit activity in the freely moving rat. Brain Res 34:171-175.

O'Keefe J, Nadel L (1978) The hippocampus as a cognitive map. Oxford: Clarendon.

O'Keefe J, Speakman A (1987) Single unit activity in the rat hippocampus during a spatial memory task. Exp Brain Res 68:1-27.

Olton DS, Branch M, Best PJ (1978) Spatial correlates of hippocampal unit activity. Exp Neurol 58:387-409.

Otto T, Eichenbaum H (1992) Neuronal activity in the hippocampus during delayed nonmatching to sample performance in rats: evidence for hippocampal processing in recognition memory. Hippocampus 2:323-334.

Quirk GJ, Muller RU, Kubie JL (1990) The firing properties of hippocampal place cells in the dark depends on the rat's recent experience. J Neurosci 10:2008-2017.

Quirk GJ, Muller RU, Kubie JL, Ranck Jr JB (1992) The positional firing properties of medial entorhinal neurons: description and comparison with hippocampal place cells. J Neurosci 12:1945-1963.

Ranck JB (1973) Studies on single neurons in dorsal hippocampal formation and septum in unrestrained rats. Exp Neurol 41:461-531.

Recce ML, O'Keefe J (1989) The tetrode: an improved technique for multi-unit extracellular recording. Soc Neurosci Abstr 15:1250.

Redish DA, Touretzky DS (1996) Cognitive maps beyond the hippocampus. Hippocampus, in press.

Seguinot V, Maurer R, Etienne AS (1993) Dead reckoning in a small mammal: the evaluation of distance. J Comp Physiol [A] 173:103-113.

Sharp PE, Kubie JL, Muller RU (1990) Firing properties of hippocampal neurons in a visually symmetrical environment: contributions of multiple sensory cues and mnemonic processes. J Neurosci 10:3093-3105.

Taube JS (1995) Head direction cells recorded in the anterior thalamic nuclei of freely moving rats. J Neurosci 15:70-86.

Taube JS, Muller RU, Ranck JB (1990) Head direction cells recorded from the postsubiculum in freely moving rats. I. Description and quantitative analysis. J Neurosci 10:420-435.

Tsodyks M, Sejnowski TJ (1995) Associative memory and hippocampal place cells. Int J Neural Sys 6:81-86.

Ungerleider LG, Mishkin M (1982) Two cortical visual systems. In: Analysis of visual behavior (Ingle DJ, Goodale MA, Wansfield RJ, eds), pp 549-586. Cambridge, MA: MIT.

Wan HS, Touretzky DS, Redish DA (1994) Towards a computational theory of rat navigation. In: Proceedings of the 1993 Connectionist Models Summer School (Mozer MC, Smolensky P, Touretzky DS, Elman JL, Weigend AS, eds), pp 11-19. Hillsdale, NJ: Erlbaum.

Wiener SI, Paul CA, Eichenbaum H (1989) Spatial and behavioral correlates of hippocampal neuronal activity. J Neurosci 9:2737-2763.

Wilson MA, McNaughton BL (1993) Dynamics of the hippocampal ensemble code for space. Science 261:1055-1058.

Worden R (1992) Navigation by fragment fitting: a theory of hippocampal function. Hippocampus 2:165-187.

Young BJ, Fox GD, Eichenbaum H (1994) Correlates of hippocampal complex-spike activity in rats performing a nonspatial radial maze task. J Neurosci 14:6553-6563. 